\title{
Assessment of natural irradiation doses in rare earth mines of Muong Hum, Bat Xat district, Lao Cai province
}

\author{
Dung Van Nguyen ${ }^{1,}$, Huan Dinh Trinh ${ }^{2}$, Tuong Van Phan ${ }^{2}$ \\ ${ }^{1}$ Hanoi University of Mining and Geology, Hanoi, Vietnam \\ ${ }^{2}$ Geological Division on Radioactive and Rare Earth Element, Hanoi, Vietnam
}

\begin{abstract}
ARTICLE INFO
ABSTRACT

Article history:

Received 01st June 2021

Revised 01 ${ }^{\text {st }}$ Sept. 2021

Accepted 30 $0^{\text {th }}$ Sept. 2021

Keywords:

Effective annual dose,

Muong Hum,

Radioactivity,

Radioactive environment,

Rare earth mines.

The rare earth mine containing high concentrations of natural radionuclides $\left(238 \mathrm{U},{ }^{232} \mathrm{Th}\right.$, and $\left.{ }^{40} \mathrm{~K}\right)$ in Muong Hum commune, Nam Pung, Bat Xat district, Lao Cai province, a mine with large reserves of rare earth resources in Vietnam, will be exploited and processed in the near future. The activity of natural radionuclides in the environment of air, soil, water, and effective annual dose are important parameters in assessing the impact of radiation on the environment when the mine goes into operating and processing rare earth ore. Investigating and determining radioactivity in soil, water, and plants at Muong Hum rare earth mine by means of radioactive gas measurement (RAD-7), gamma radiation dose rate (DKS-96), sample analysis using an ICP-MS mass spectrometer, will be performed in this study. The results showed that some soil samples had radionuclides activity ${ }^{238} U$, $232 \mathrm{Th}$ higher than the allowed standard. The annual effective dose value in the region is 6.1 times higher than the world average (2.4 mSv/year). The obtained results are the basis for monitoring the impact of the radioactive environment and providing solutions to minimize the effects of radioactive substances on the ecological environment when the mine goes into mining and processing of rare earth ores.
\end{abstract}

Copyright (C) 2021 Hanoi University of Mining and Geology. All rights reserved.

${ }^{*}$ Corresponding author

E - mail: nguyenvandung@humg.edu.vn

DOI: $10.46326 / J M E S .2021 .62(5) .10$ 


\title{
Đánh giá liều chiếu xạ tự nhiên khu vực mỏ đất hiếm Mường Hum, huyện Bát Xát, tỉnh Lào Cai
}

\author{
Nguyễn Văn Dũng 1, ${ }^{*}$, Trịnh Đình Huấn ${ }^{2}$, Phan Văn Tường 2 \\ ${ }^{1}$ Trường Đại học Mỏ - Địa chất, Hà Nội, Việt Nam \\ ${ }^{2}$ Liên đoàn Địa chất Xạ - Hiếm, Hà Nội, Việt Nam
}

\begin{abstract}
THÔNG TIN BÀI BÁO
TÓM TẮT

Quá trình:

Nhận bài 01/6/2021

Sứa xong 01/9/2021

Chap nhận đăng 30/9/2021

Tù̀ khóa:

Hoạt độ phóng xạ,

Liều hiệu dụng hàng năm,

Mỏ đất hiếm,

Mường Hum,

Môi trường phóng xạ.

Mỏ đất hiếm chứa hàm lượng cao các nhân phóng xa tự nhiên ${ }^{238} U$, ${ }^{232}$ Th và ${ }^{40} \mathrm{~K}$ ) thuộc xã Mường Hum, Nậm Pung, huyện Bát X'́t, tỉnh Lào Cai, là mỏ có trũ lương tài nguyên đất hiếm lớn của Việt Nam sẽ được đưa vào khai thác, chế biến trong thời gian tới. Hoạt độ̣ các nhân phóng xạ tự nhiên trong môi trường không khí, đất, nước và liều hiệu dưng hàng năm là những thông số quan trong trong việc đánh giá ảnh hường của phóng xạ đến môi trường khi mỏ đi vào hoạt động khai thác, chế biến quặng đầt hiếm. Điều tra, xác định hoạt độ phóng xạ trong đất, nước, thực vật tại mỏ đất hiếm Mường Hum bằng hẹ phương pháp đo khí phóng xạ (RAD7), suất liều bức xạ gamma (DKS-96), phân tích mẫu băng khối phổ kế ICP-MS được thực hiện trong nghiên cúu này. Kết quả cho thấy, một số mẫu đất có hoạt độ các hạt nhân phóng xạ ${ }^{238} U$, ${ }^{232}$ Th cao hơn so với tiêu chuẩn cho phép. Giá trị liều hiệu dụng hàng năm tại khu vực cao gấp 6,1 lần so với trung bình thế giới $(2,4 \mathrm{mSv} / \mathrm{năm})$. Kết quả đạt được là cơ sở để theo dõi tác động của môi trường phóng xạ và đưa ra các giải pháp giảm thiểu ảnh hưởng của các chất phóng xạ đến môi trường sinh thái khi mỏ đi vào khai thác, chế biến quặng đầt hiếm.
\end{abstract}

(C) 2021 Trường Đại học Mỏ - Địa chất. Tất cả các quyền được bảo đảm.

\section{Mở đầu}

Các hạt nhân phóng xạ tự nhiên bao gồm ${ }^{238 U}$, ${ }^{232} \mathrm{Th}$ và ${ }^{40} \mathrm{~K}$ có trong lớp vỏ Trái Đất, chúng tồn tại trong đá quặng, đất, thực vật, nước và không khí. Bức xạ gamma từ các hạt nhân phóng xạ tự nhiên và các tia vũ trụ tạo thành sự phơi nhiễm chiếu xạ ngoài gây tác động đến sức khỏe và môi trường

\footnotetext{
*Tác giả liên hệ

E - mail: nguyenvandung@humg.edu.vn

DOI: 10.46326/JMES.2021.62(5).10
}

sinh thái (UNSCEAR, 2000). Các hạt nhân phóng xạ tự nhiên ${ }^{226} \mathrm{Ra},{ }^{238 \mathrm{U}},{ }^{40} \mathrm{~K},{ }^{232} \mathrm{Th}$ và các đồng vị con, cháu của chúng trong đất bề mặt gây ra liều bức xạ gamma trên mặt đất và đóng góp khoảng 80\% liều hiệu dụng hàng năm tác động đến người dân sinh sống trong khu vực (Karahan và Bayulken, 2000; Erees FS và nnk., 2006; Duong và nnk., 2021). Các hạt nhân phóng xạ trong đất có thể được di chuyển vào cây cối và tích lũy trong cơ thể con người thông qua việc ăn lương thực và rau quả (Azeez và nnk., 2019; Cengiz, 2019; Duong và nnk., 2021; Van và nnk., 2020). Phóng xạ tự nhiên phụ thuộc chủ yếu vào các đặc điểm địa chất, địa 
lý, môi trường và xuất hiện ở các mức độ khác nhau trong các loại đất, đá của từng khu vực trên thế giới (UNSCEAR, 2000). Trong nội dung bài báo này,các tác giả chủ yếu nghiên cứu xác định hoạt độ hạt nhân phóng xạ tự nhiên và đánh giá mức liều chiếu hàng năm tại khu vực mỏ đất hiếm Mường Hum, huyện Bát Xát, tỉnh Lào Cai.

Mỏ đất hiếm Mường Hum thuộc các xã Nậm Pung và Mường Hum, huyện Bát Xát, tỉnh Lào Cai, được giới hạn bởi tọa độ $22^{0} 51^{\prime} \div 22^{05} 5^{\prime}$ vĩ độ Bắc và $103^{0} 68^{\prime} \div 103^{074} 4^{\prime}$ kinh độ đông (Hình 1$)$. Địa hình khu vực thuộc dạng phức tạp, phần dọc trung tâm theo hướng tây bắc - đông nam, địa hình đồi núi thấp, bao bọc hai bên sườn là hai dãy núi cao bị phân cắt mạnh. Độ cao địa hình thay đổi $500 \div 2.000 \mathrm{~m}$ tạo nên nhiều thành vách, phân cắt bởi các hệ thống sông suối. Đặc điểm địa chất của khu vực gồm các hệ tầng: Sin Quyền (PP-MPsq), Bản Nguồn $\left(\mathrm{D}_{1} b n\right)$, Cha Pả (NPcp), Bản Páp ( $\mathrm{D}_{1-}$ ${ }_{2} b p$ ), Nậm Xe - Tam Đường (aG-aSy/Ent), Mường Hum (aG/PZ $\left.{ }_{2} m h\right)$, Đệ Tứ $(d p Q)$. Theo kết quả điều tra đánh giá của Liên đoàn Địa chất Xạ - Hiếm cho thấy, đây là mỏ đất hiếm có trữ lượng lớn, tài nguyên đất hiếm tại chỗ 175.0000 tấn $\mathrm{TR}_{2} \mathrm{O}_{3}$, tài nguyên đất hiếm nhóm nặng 37.500 tấn (Bộ Công thương, 2011; Trần Bình Trọng và nnk., 2005; Bùi Tất Hợp và nnk., 2010; Nguyễn Văn Dũng và nnk., 2020).

Thành phần khoáng vật quặng đất hiếm ở mỏ Mường Hum bao gồm chủ yếu là tập hợp các khoáng vật nặng bền vững trong điều kiện ngoại sinh, đặc trưng cho loại hình quặng sa khoáng gồm: monazit, thori, oxinit, bastnezit, checchit, smacskit, thạch anh, manhetit, ilmenit,

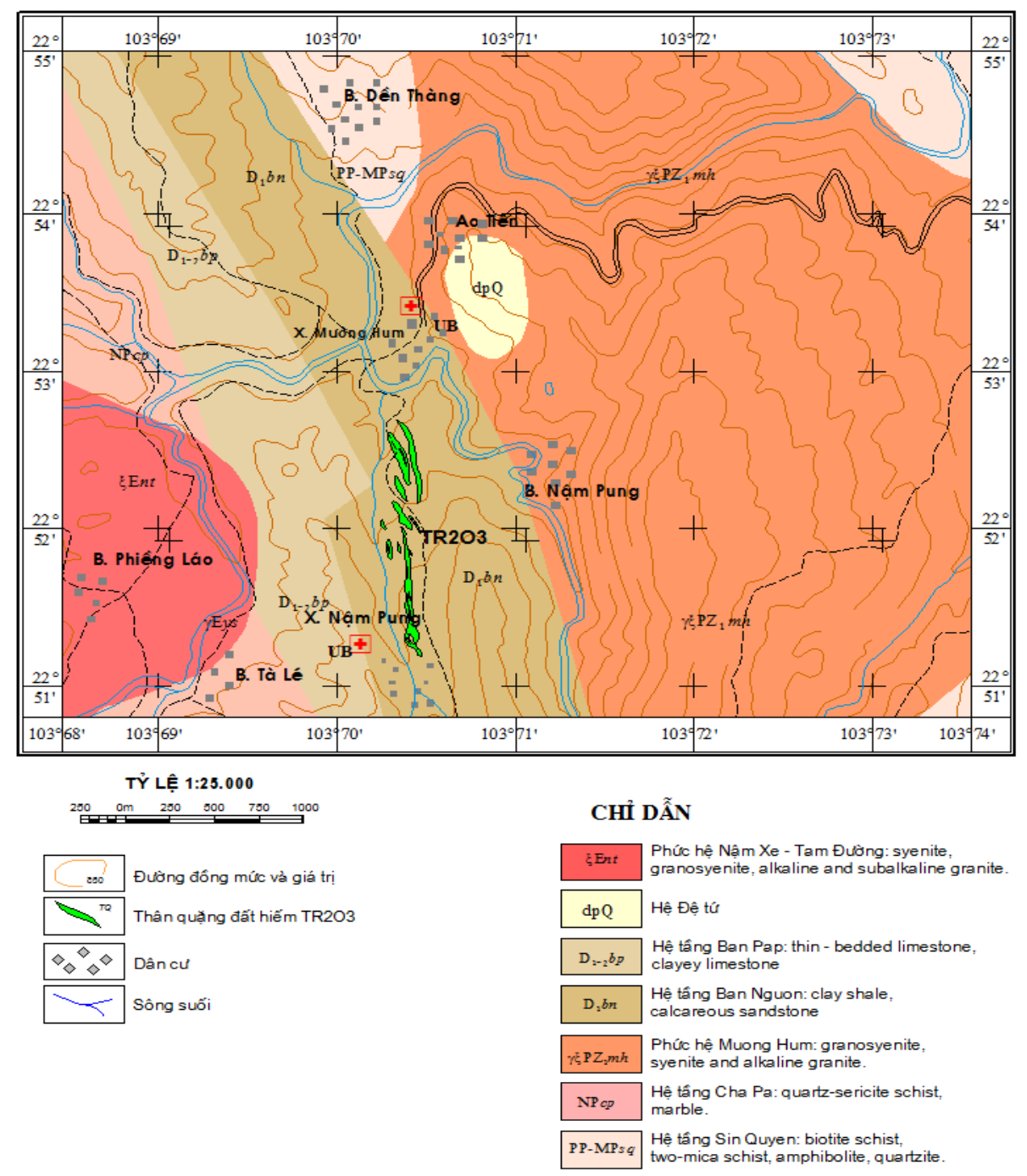

Hình 1. So đồ địa chất khu vực mỏ đất hiếm Mường Hum (Liên đoàn Địa chất Xạ - Hiếm, 2018). 
inmenorutin, zircon, octit, sphen, barit. Hàm lượng $\mathrm{TR}_{2} \mathrm{O}_{3}$ trong mỏ dao động $0,78 \div 3,02 \%$, trung bình $1,45 \% \mathrm{TR}_{2} \mathrm{O}_{3}$; thori từ $0,106 \div 0,188 \%$ $\mathrm{ThO}_{2}$, trung bình $0,157 \% \quad \mathrm{ThO}_{2}$; urani từ $0,012 \div 0,028 \% \mathrm{U}_{3} \mathrm{O}_{8}$, trung bình $0,016 \% \mathrm{U}_{3} \mathrm{O}_{8}$. Kết quả phân tích ICP-MS cho thấy, tỷ lệ đất hiếm nhóm nặng trong mỏ dao động $16 \div 40 \%$, trung bình $22 \%$ so với tổng oxit đất hiếm (Bộ Công thương, 2011; Trần Bình Trọng và nnk., 2005; Bùi Tất Hợp và nnk., 2010; Nguyễn Văn Dũng và nnk., 2020).

Hàm lượng các chất phóng xạ trong đất hiếm đã gây ra mức liều chiếu xạ cao cho khu vực $(>14,0$ $\mathrm{mSv} / \mathrm{năm}$ ) ảnh hưởng đến môi trường và sức khỏe người dân thuộc bản Nậm Pung, Mường Hum đang sinh sống trong khu mỏ và khu lân cận (Trần Bình Trọng và nnk., 2005; Bùi Tất Hợp và nnk., 2010; Nguyễn Văn Dũng và nnk., 2020).

\section{Phương pháp nghiên cứu}

Để đánh giá ảnh hưởng của phóng xạ đến môi trường khu vực nghiên cứu, nhóm tác giả đã sử dụng các phương pháp sau:

- Đo suất liều gamma môi trường. Với thiết bị sử dụng là máy Inspector do Nga sản xuất, với độ chính xác $0.01 \mu \mathrm{Sv} / \mathrm{h}$;

- Đo khí phóng xạ trong không khí (Rn, Tn) bằng thiết bị RAD-7, độ nhạy $5 \mathrm{~Bq} / \mathrm{m}^{3}$;

- Đo phổ gamma môi trường bằng thiết bị RAD-6;

- Phân tích hàm lượng các nhân phóng xạ U, Th, K, Ra bằng phương pháp ICP-MS.

Sơ đồ vị trí khảo sát được trình bày ở Hình 2.

\subsection{Liều hiệu dụng hàng năm}

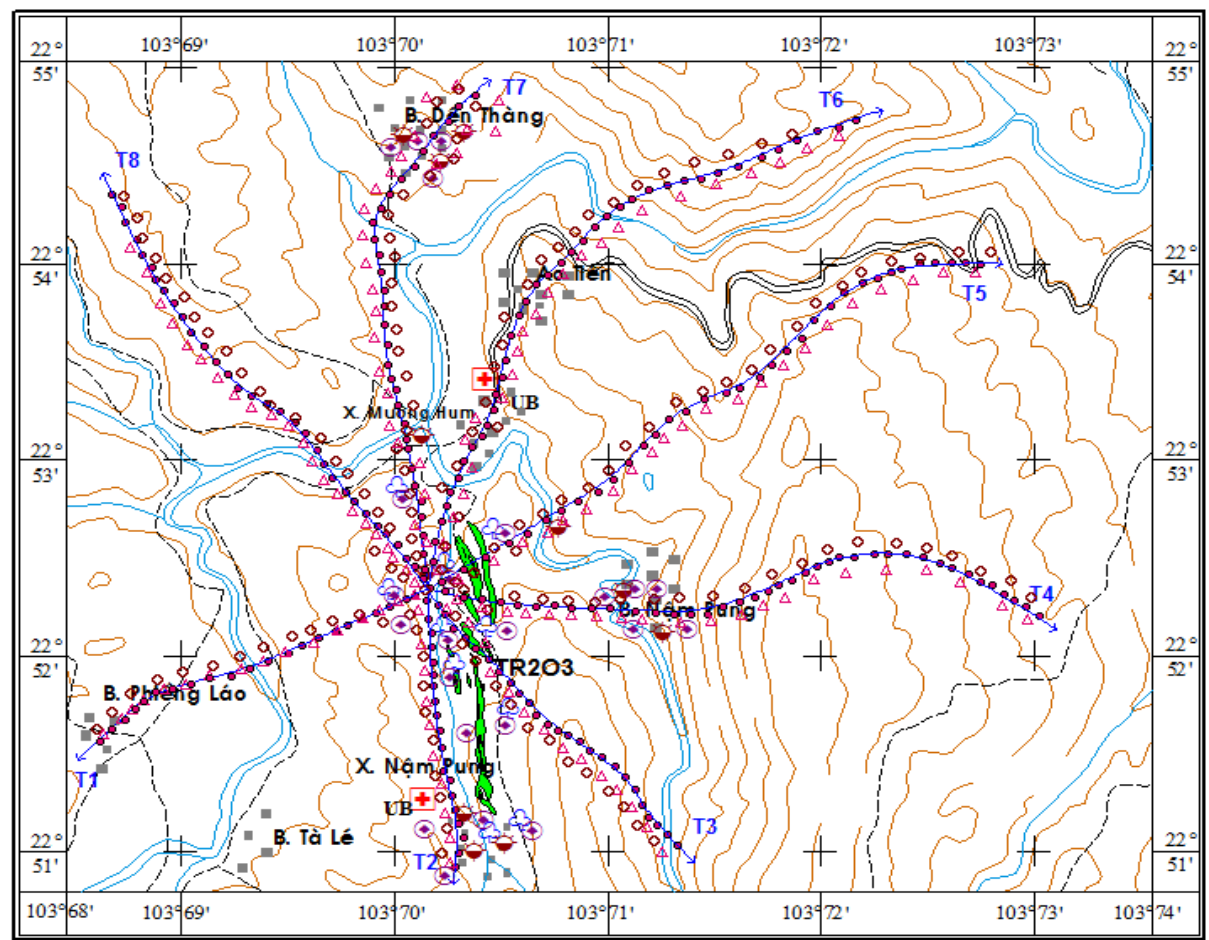

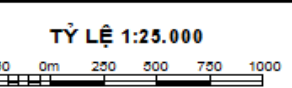
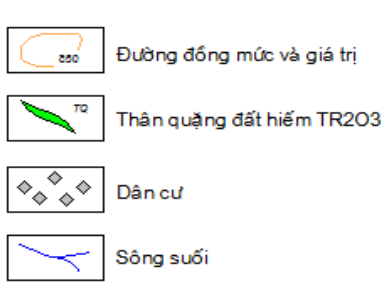

\section{CHİ DẪN}

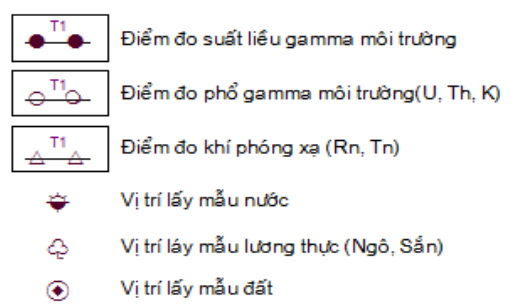

Hình 2. Sơ đồ khảo sát khu vực nghiên cứu. 


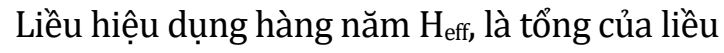
chiếu ngoài và liều chiếu trong, được xác định theo công thức sau:

Trong đó:

$$
\mathrm{H}_{\mathrm{eff}}=\mathrm{H}_{\mathrm{n}}+\mathrm{H}_{\mathrm{t}}(\mathrm{mSv} / \text { năm })
$$

- $\mathrm{H}_{\mathrm{n}}(\mathrm{mSv} / \mathrm{năm})$ - liều chiếu ngoài gây bởi bức xạ gamma, được đo tại vị trí cách mặt đất $1 \mathrm{~m}$, xác định theo công thức sau:

$$
\mathrm{H}_{\mathrm{n}}=8760 \times \mathrm{H}_{\mathrm{SL}},(\mathrm{mSv} / \text { năm })
$$

Trong đó: $\mathrm{H}_{\mathrm{SL}}(\mu \mathrm{Sv} / \mathrm{h})$ - suất liều chiếu ngoài trong môi trường xung quanh;

- $\mathrm{H}_{\mathrm{t}}(\mathrm{mSv} / \mathrm{năm})$ - liều chiếu trong gồm các thành phần:

+ Liều chiếu trong qua đường hô hấp $\left(\mathrm{H}_{\mathrm{p}}\right)$ do hít phải khí phóng xạ radon, toron được xác định theo công thức sau:

$$
\mathrm{H}_{\mathrm{p}}=\mathrm{H}_{\mathrm{Rn}}+\mathrm{H}_{\mathrm{Tn}}(\mathrm{mSv} / \mathrm{năm})
$$

Ở đây: $\mathrm{H}_{R n}=0,047 \mathrm{C}_{\mathrm{Rn}}\left(\mathrm{Bq} / \mathrm{m}^{3}\right), \mathrm{H}_{\mathrm{Tn}}=0,007 \mathrm{C}_{\mathrm{Tn}}$ $\left(\mathrm{Bq} / \mathrm{m}^{3}\right)$ với $\mathrm{C}_{\mathrm{Rn}}$ là nồng độ khí radon $\left({ }^{222} \mathrm{Rn}\right)$ trong không khí và $\mathrm{C}_{\mathrm{Tn}}$ là nồng độ khí toron $\left({ }^{220} \mathrm{Rn}\right)$ không khí.

+ Liều chiếu trong qua đường tiêu hóa $\left(\mathrm{H}_{\mathrm{d}}\right)$ (thức ăn và nước uống), được xác định bởi các công thức sau:

$\mathrm{Hd}(\mathrm{mSv} / \mathrm{năm})=(6,2 \cdot 10-6 \mathrm{AK}+2,8 \cdot 10-4 \mathrm{ARa}$ + 2,3.10-4ATh + 4,4.10-5AU)md, (4)

Trong đó: $A_{K}, A_{R a}, A_{T h}, A_{U}(B q / k g)$ là hoạt độ phóng xạ của Kali, Rađi, Thori, Urani trong một lít nước hoặc một kg thực phẩm, tương ứng; $\mathrm{m}_{\mathrm{d}}$ là lượng nước hoặc thực phẩm trung bình tiêu thụ một người trong một năm (800 lít nước và 650 kg thức ăn).

\subsection{Hoạt độ bức xạ trong các mẫu đất}

Hoạt độ bức xạ trong đất được xác định bởi công thức sau:

$$
\mathrm{A}=\mathrm{A}_{\mathrm{Ra}}+1,3 \mathrm{~A}_{\mathrm{Th}}+0,085 \mathrm{~A}_{\mathrm{K}}(\mathrm{Bq} / \mathrm{kg})
$$

Với $A_{R a}, A_{T h}, A_{K}(B q / k g)$ lần lượt là các hoạt độ của các nhân phóng xạ Ra, Th, K.

\subsection{Phưong pháp đánh giá sai số}

Để đánh giá môi trường phóng xạ tự nhiên, nghiên cứu này đã sử dụng tổ hợp các phương pháp sau:

- Đo liều bức xạ gamma để xác định liều chiếu ngoài gây bởi bức xạ gamma trong khu vực nghiên cứu;

- Đo khí phóng xạ để xác định nồng độ radon, toron trong không khí xung quanh, do đó tính toán liều chiếu trong qua đường hô hấp;

- Xác định hoạt độ các chất phóng xạ urani, thori, kali trong các mẫu lương thực, nước để tính toán liều chiếu trong qua đường tiêu hóa.

Sai số các phép đo được xác định bởi các công thức sau:

$$
\begin{aligned}
& \text { Sai số tuyệt đối: } \sigma=\sqrt{\frac{\sum_{i=1}^{n}\left(x_{i}-y_{i}\right)^{2}}{2 n}} \\
& \text { Sai số tương đối: } \delta=\frac{\sigma}{R} \cdot 100 \% \text { với } \\
& \qquad R=\frac{1}{2 n} \sum_{i=1}^{n}\left(x_{i}+y_{i}\right)
\end{aligned}
$$

Với $\mathrm{n}$ - số điểm đo kiểm tra; $\mathrm{x}_{\mathrm{i}}, \mathrm{y}_{\mathrm{i}}$ - giá trị đo chính và đo lặp.

Sau khi tiến hành khảo sát và phân tích xử lý dữ liệu, kết quả đánh giá sai số của các phép đo theo công thức (6) và $(7)$ được trình bày trong Bảng 1. Kết quả tính sai số cho thấy các số liệu khảo sát đảm bảo tin cậy (Bảng 1).

\section{Kết quả và thảo luận}

Bảng 1. Đánh giá sai số của các phép đo.

\begin{tabular}{|c|c|c|c|c|c|}
\hline \multirow{2}{*}{ Phương pháp khảo sát } & \multirow{2}{*}{ Điểm đo } & $\begin{array}{c}\text { Sai số tương } \\
\text { đối (\%) }\end{array}$ & \multicolumn{2}{|c|}{ Sai số tuyệt đối (\%) } & \multirow{2}{*}{$\begin{array}{c}\text { Ngưỡng cho } \\
\text { phép (\%) }\end{array}$} \\
\cline { 4 - 5 } & & Giá trị & Đơn vị & \\
\hline \multicolumn{7}{|c|}{ Phương pháp đo suất liều gamma } \\
\hline Đo suất liều gamma & 200 & 2,45 & 0,02 & $\mu \mathrm{Sv} / \mathrm{h}$ & $\leq 10$ \\
\hline \multicolumn{7}{|c|}{ Phương pháp đo khí phóng xạ } \\
\hline Radon (222Rn) & 41 & 11,45 & 6,55 & $\mathrm{~Bq} / \mathrm{m}^{3}$ & $\leq 15$ \\
\hline Toron ( $\left.{ }^{220} \mathrm{Rn}\right)$ & 41 & 8,37 & 8,45 & $\mathrm{~Bq} / \mathrm{m}^{3}$ & $\leq 15$ \\
\hline \multicolumn{7}{|c|}{ Phương pháp đo phổ gamma } \\
\hline Kênh Kali & 37 & 5,12 & 1,23 & $\%$ & $\leq 10$ \\
\hline Kênh Uranium & 37 & 6,56 & 1,98 & $\mathrm{ppm}$ & $\leq 10$ \\
\hline Kênh Thorium & 37 & 2,47 & 2,77 & $\mathrm{ppm}$ & $\leq 10$ \\
\hline
\end{tabular}




\subsection{Các thành phần môi trường phóng xạ khu vực khảo sát}

\subsubsection{Giá trị suất liều bức xạ gamma}

Kết quả khảo sát cho thấy liều gamma ở vị trí $0 \mathrm{~m}$ có giá trị thay đổi $0,14 \div 3,12 \mu \mathrm{Sv} / \mathrm{h}$, trung bình $0,86 \mu \mathrm{Sv} / \mathrm{h}$; ở vị trí $1 \mathrm{~m}$, giá trị thay đổi $0,11 \div 2,93$ $\mu \mathrm{Sv} / \mathrm{h}$, trung bình $0,71 \mu \mathrm{Sv} / \mathrm{h}$ (Bảng 2).

Bảng 2. Đặc trung thống kê suất liều gamma.

\begin{tabular}{|c|c|c|}
\hline \multirow{2}{*}{ Thông số } & \multicolumn{2}{|c|}{$\begin{array}{c}\text { Giá trị suất liều gamma } \\
(\mu \mathrm{Sv} / \mathrm{h})\end{array}$} \\
\cline { 2 - 3 } & $0 \mathrm{~m}$ & $1 \mathrm{~m}$ \\
\hline Nhỏ nhất & 0,14 & 0,11 \\
\hline Lớn nhất & 3,12 & 2,93 \\
\hline Trung bình & 0,86 & 0,71 \\
\hline
\end{tabular}

Tại vị trí 1 m so với mặt đất, giá trị suất liều bức xạ gamma nhỏ hơn $0,3 \mu \mathrm{Sv} / \mathrm{h}$ ở khu vực bên ngoài thân quặng đất hiếm. Mức liều gamma $0,3 \div 0,6 \mu \mathrm{Sv} / \mathrm{h}$ được xác định ở khu vực tiếp giáp giữa thân quặng và khu vực phi quặng, càng vào gần thân quặng đất hiếm giá trị suất liều gamma tăng cao, tại vị trí thân quặng đạt giá trị 3,12 $\mu \mathrm{Sv} / \mathrm{h}$. Theo tiêu chuẩn của Nga và Việt Nam (Bộ Khoa học và Công nghệ, 2012; NRB-99, 1999), thì đây là khu vực vượt quá tiêu chuẩn cho phép đối với suất liều bức xạ gamma.

\subsubsection{Nồng độ khí phóng xạ radon, toron}

Nồng độ của khí radon (222Rn) trong không khí tại khu vực $3,2 \div 1030,5 \mathrm{~Bq} / \mathrm{m}^{3}$ và trung bình $100,4 \mathrm{~Bq} / \mathrm{m}^{3}$; nồng độ của khí toron $(220 \mathrm{Rn})$ $7,8 \div 4762,4 \mathrm{~Bq} / \mathrm{m}^{3}$ và trung bình $489,2 \mathrm{~Bq} / \mathrm{m}^{3}$ (Bảng 3). Tại khu vực có mật độ dân số cao, như các bản thuộc xã Mường Hum, Nậm Pung, giá trị nồng độ radon cao hơn mức khuyến cáo về nồng độ khí radon trong nhà ở theo tiêu chuẩn Việt Nam (TCVN 7889:2008).

Bảng 3. Nồng độ khí phóng xạ radon.

\begin{tabular}{|c|c|c|}
\hline \multirow{2}{*}{ Thông số } & \multicolumn{2}{|c|}{$\begin{array}{c}\text { Nồng độ khí phóng xạ } \\
\left(\mathrm{Bq} / \mathrm{m}^{3}\right)\end{array}$} \\
\cline { 2 - 3 } & ${ }^{222} \mathrm{Rn}$ & ${ }^{220} \mathrm{Rn}$ \\
\hline Nhỏ nhất & 3,2 & 7,8 \\
\hline Lớn nhất & 1030,5 & 4762,4 \\
\hline Trung bình & 100,4 & 489,2 \\
\hline
\end{tabular}

Theo tiêu chuẩn của Việt Nam (TCVN 7889:2008), không được phép xây dựng nhà mới ở những khu vực có nồng độ khí phóng xạ radon vượt quá $100 \mathrm{~Bq} / \mathrm{m}^{3}$.

\subsubsection{Hoạt độ alpha, bêta trong nước}

Kết quả phân tích hoạt độ alpha và bêta trong nước sinh hoạt tại các hộ dân cho thấy: giá trị hoạt độ alpha 0,017 $\div 0,087 \mathrm{~Bq} / \mathrm{l}$, trung bình $0,04 \mathrm{~Bq} / \mathrm{l}$; hoạt độ bêta $0,195 \div 0,886 \mathrm{~Bq} / \mathrm{l}$, trung bình là $0,500 \mathrm{~Bq} / \mathrm{l}$. So sánh với quy chuẩn Việt $\mathrm{Nam}$ về chất lượng nước mặt, giá trị giới hạn ngưỡng của hoạt độ alpha và bêta lần lượt là $0,1 \mathrm{~Bq} / \mathrm{l}$ và 1,0Bq/l (QCVN 08-MT:2015/BTNMT). Do đó, tổng hoạt độ của alpha và bêta trong các mẫu nước nằm trong giới hạn cho phép (Bảng 4).

Bảng 4. Đặc trưng thống kê tổng hoạt độ alpha và bêta trong nước.

\begin{tabular}{|c|c|c|}
\hline \multirow{2}{*}{ Thông số } & \multicolumn{2}{|c|}{ Hoạt độ $(\mathrm{Bq} / \mathrm{l})$} \\
\cline { 2 - 3 } & Alpha & Bêta \\
\hline Nhỏ nhất & 0,017 & 0,195 \\
\hline Lớn nhất & 0,087 & 0,886 \\
\hline Trung bình & 0,040 & 0,500 \\
\hline
\end{tabular}

3.1.4. Hoạt độ các nhân phóng xạ trong cây lương thực (ngô, sắn)

Kết quả phân tích hàm lượng các nguyên tố phóng xạ trong các mẫu cây lương thực đã chỉ ra rằng các nhân phóng xạ ${ }^{226} \mathrm{Ra},{ }^{238 \mathrm{U}},{ }^{232} \mathrm{Th}$ và ${ }^{40} \mathrm{~K}$ có mặt trong hầu hết các mẫu lương thực trong khu vực mỏ đất hiếm Mường Hum (Bảng 5).

Bảng 5. Đặc trung thống kê hoạt độ các nhân phóng xạ trong mẫu lương thực (ngô, sắn).

\begin{tabular}{|c|c|c|c|c|}
\hline \multirow{2}{*}{ Thông số } & \multicolumn{4}{|c|}{ Hoạt độ phóng xạ (Bq/kg) } \\
\cline { 2 - 5 } & ${ }^{226} \mathrm{Ra}$ & ${ }^{238} \mathrm{U}$ & ${ }^{232} \mathrm{Th}$ & ${ }^{40} \mathrm{~K}$ \\
\hline Nhỏ nhất & 0,04 & 0,17 & 1,33 & 112,12 \\
\hline Lớn nhất & 40,04 & 23,34 & 45,48 & 410,45 \\
\hline Trung bình & 6,43 & 6,15 & 8,65 & 223,21 \\
\hline
\end{tabular}

So với tiêu chuẩn (NRB-99, 1999; TCVN 7538 - 1:2006; IAEA, 2006; ICRP, 2007), hoạt độ các chất phóng xạ trong các mẫu lương thực vượt quá giới hạn cho phép, có nghĩa là mẫu lương thực được trồng trên khu vực mỏ đất hiếm Mường Hum có thành phần liều chiếu trong qua đường 
tiêu hóa vượt quá tiêu chuẩn cho phép (IAEA, 2001).

\subsubsection{Hoạt độ của các nguyên tố phóng xạ trong đất}

Phân tích thống kê về hoạt độ của các nguyên tố phóng xạ trong đất đã chỉ ra rằng các đồng vị phóng xạ như ${ }^{226} \mathrm{Ra},{ }^{238} \mathrm{U},{ }^{232} \mathrm{Th}$ và ${ }^{40} \mathrm{~K}$ có mặt trong hầu hết các mẫu đất tại khu vực mỏ đất hiếm Mường Hum (Bảng 6).

Bảng 6. Đặc trưng thống kê hoạt độ phóng xạ trong mẫu đất.

\begin{tabular}{|c|c|c|c|c|}
\hline \multirow{2}{*}{ Thông số } & \multicolumn{4}{|c|}{ Hoạt độ phóng xạ (Bq/kg) } \\
\cline { 2 - 5 } & $226 \mathrm{Ra}$ & $238 \mathrm{U}$ & $232 \mathrm{Th}$ & $40 \mathrm{~K}$ \\
\hline Nhỏ nhất & 148,4 & 117,3 & 418,9 & 165,6 \\
\hline Lớn nhất & 2515,4 & $1.844,4$ & $3.898,5$ & $2.529,2$ \\
\hline Trung bình & 372,3 & 281,5 & 806,7 & 384,8 \\
\hline
\end{tabular}

Kết quả phân tích các mẫu đất ở Bảng 6 cho thấy, hoạt độ các nhân phóng xạ tự nhiên trong đất của một số mẫu vượt quá giới hạn $>1.000 \mathrm{~Bq} / \mathrm{kg}$ (UNSCEAR, 2000; IAEA, 2001). Các mẫu đất này được lấy tại nơi có sử dụng đất để trồng cây lương thực như ngô, sắn, bắp cải, rau cải,... và người dân xây nhà để ở. Kết quả cho thấy sự phân bố các mẫu đất có hoạt độ phóng xạ cao chủ yếu nằm ở khu vực chứa quặng đất hiếm. Theo các giá trị giới hạn ngưỡng của các chất phóng xạ trong vật liệu xây dựng, đất, đá thì trong khu vực mỏ đất hiếm Mường Hum không được cấp phép để định cư lâu dài, xây dựng các công trình dân dụng,...

\section{2. Đánh giá phân vùng môi trưòng phóng xa khu vực mỏ đất hiếm Mưòng Hum}

\subsubsection{Cơ sở pháp lý phân vùng đánh giá môi trường phóng xạ}

Theo ICRP, can thiệp là các hoạt động của con người nhằm giảm thiểu mức chiếu xạ hiện có trước khi quyết định về các hành động an toàn bức xạ được đưa ra. Đối với các mỏ khoáng sản có chứa chất phóng xạ, can thiệp là các hoạt động cách ly, che chắn để giảm liều chiếu ngoài; có hệ thống thông gió, lọc bụi... để giảm nồng độ khí phóng xạ (radon, thoron) và liều chiếu trong qua đường hô hấp.

\section{- Các múrc tham chiếu an toàn phóng xạ}

Giá trị tham chiếu được xem là mức liều chiếu xạ mà trên mức đó cần phải có các hành động bảo vệ thích hợp được thực hiện. Ủy ban An toàn Phóng xạ Quốc tế (ICRP) đề ra nguyên tắc can thiệp trong trường hợp chiếu xạ tự nhiên là các hành động can thiệp phải được luận chứng và tối ưu. Mức liều hiện thời hàng năm $10 \mathrm{mSv}$ được coi là mức khuyến cáo để bắt đầu xem xét các hành động can thiệp (Hình 3).

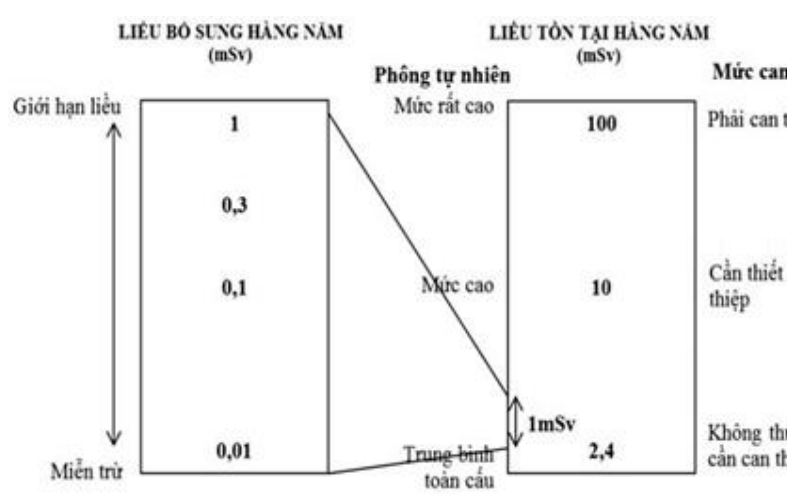

Hình 3. Múc liều khuyến cáo can thiệp trong chiếu xạ tự nhiên (ICRP, 2000).

Giới hạn nồng độ radon trong không khí nơi các ngôi nhà mới đang được xây dựng là $\leq 100$ $\mathrm{Bq} / \mathrm{m}^{3}$ và để sử dụng các tòa nhà hiện có là $\leq 200$ $\mathrm{Bq} / \mathrm{m}^{3}$.

Suất liều gamma của bức xạ không vượt quá $0,3 \mu \mathrm{Sv} / \mathrm{h}$.

\subsubsection{Nguyên tắc khoanh vùng bị ô nhiễm môi trưòng phóng xạ}

Khu vực dự kiến bị ô nhiễm bởi bức xạ tự nhiên xảy ra khi nó đáp ứng một trong các điều kiện sau (UNSCEAR, 2000; Bộ Khoa học và Công nghệ, 2012; TCVN 7889:2008; IAEA, 2000):

- Khu vực có tổng liều bức xạ > 10 mSv/năm;

- Khu vực có giá trị suất liều gamma > 0,6 $\mu \mathrm{Sv} / \mathrm{h}$, hoặc có tổng liều bức xạ > 7,0 mSv/năm;

- Khu vực có tổng hoạt độ phóng xạ trong đất $>370 \mathrm{~Bq} / \mathrm{kg}$.

3.2.3. Bản đồ phân vùng môi trường phóng xạ khu vực mỏ đất hiếm Mường Hum

Theo các công thức (1), (2) và (3), nhóm tác giả đã tính được tổng liều bức xạ hàng năm cho khu vực nghiên cứu. So sánh với các tiêu chuẩn Việt Nam (Bộ Khoa học và Công nghệ, 2012) và quốc tế (UNSCEAR, 2000; NRB-99, 1999) đã xây dựng được bản đồ phân vùng ô nhiễm phóng xạ tại khu vực mỏ đất hiếm Mường Hum (Hình 4). 
Trong đó, mỏ đất hiếm Mường Hum chia ra các khu vực có mức độ ô nhiễm phóng xạ khác nhau nhu sau:

- Khu vực có $\mathrm{H}_{\text {eff }}>3,6 \mathrm{mSv} /$ năm, chiếm diện tích 10,4 km² bao gồm toàn bộ mỏ đất hiếm Mường Hum có hộ dân của xã Nậm Pung, Mường Hum đang sinh sống.

- Khu vực có $\mathrm{H}_{\text {eff }}>10 \mathrm{mSv} / \mathrm{năm}$ (mức cần có các hành động can thiệp để giảm tổng liều bức xạ xuống < $10 \mathrm{mSv} /$ năm) nằm phủ trên toàn bộ thân quặng khu vực mỏ đất hiếm Mường Hum, chiếm diện tích $>5,4 \mathrm{~km}^{2}$. Khu vực kiểm soát có mức tổng liều bức xạ tiềm tàng lớn $>6 \mathrm{mSv} /$ năm và $<10$ $\mathrm{mSv} /$ năm, chiếm 6,5km² (Bộ Khoa học và Công nghệ, 2012). Đây là khu vực cần phải áp dụng các biện pháp bảo vệ và các quy định an toàn nhằm kiểm soát sự chiếu xạ hoặc ngăn ngừa nhiễm bẩn phóng xạ lan rộng trong điều kiện làm việc bình thường, ngăn ngừa hoặc hạn chế mức độ chiếu xạ tiềm tàng cho người dân đang sinh sống và làm việc trong khu vực.

- Khu vực có nồng độ radon trong không khí $\mathrm{NRn}>100 \mathrm{~Bq} / \mathrm{m}^{3}$, chiếm diện tích 4,5km². Theo tiêu chuẩn Việt Nam (TCVN 7889:2008), nồng độ Rn trong không khí > $100 \mathrm{~Bq} / \mathrm{m}^{3}$ là không được phép xây dựng nhà ở mới.

Kết quả nghiên cứu cho thấy, hoạt độ của hạt nhân phóng xạ $\left({ }^{238} \mathrm{U},{ }^{232} \mathrm{Th},{ }^{40} \mathrm{~K}\right)$ đối với các mầu
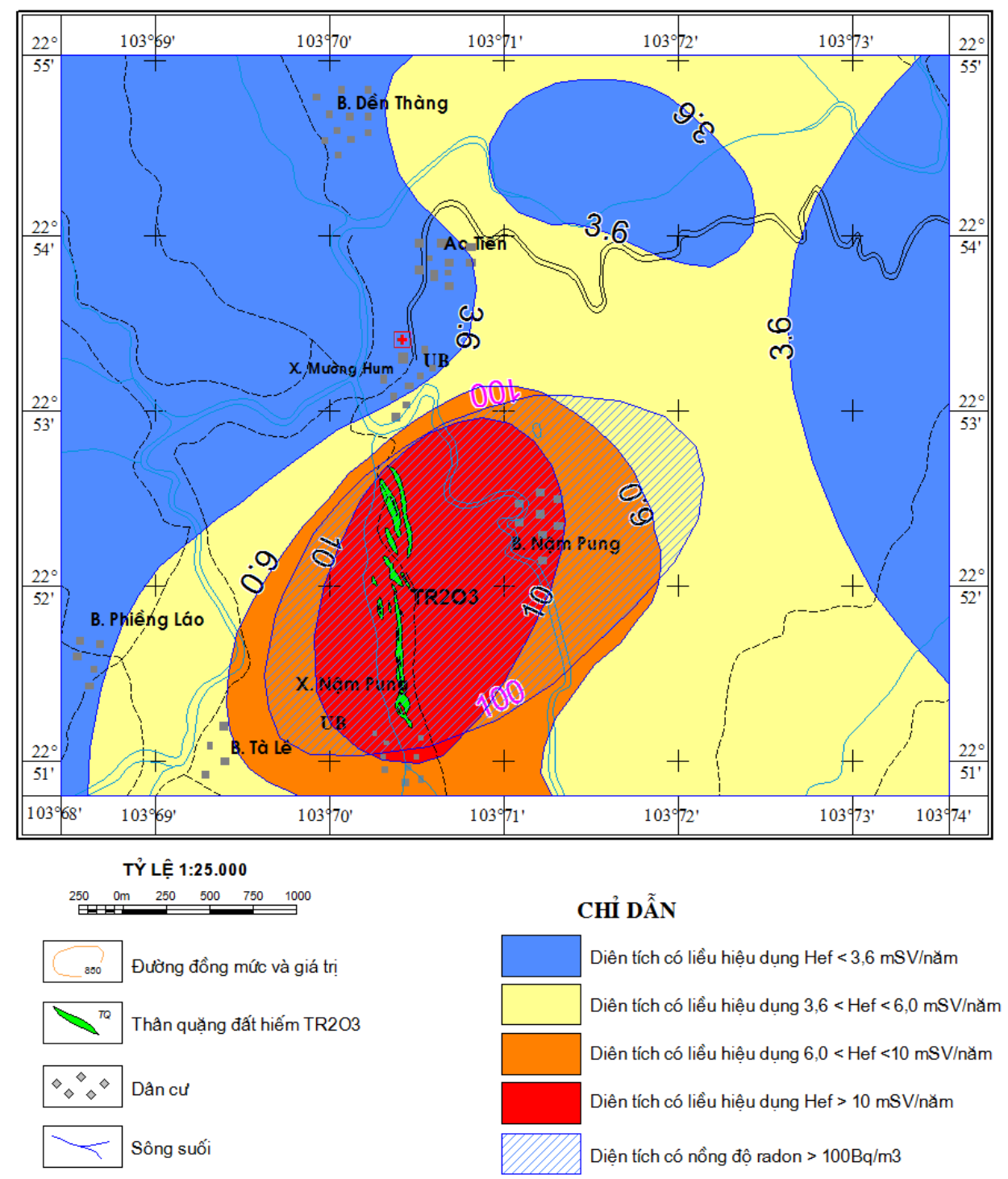

Hình 4. Bản đồ phân vùng môi trường phóng xạ mỏ đất hiếm Mường Hum. 
đất trong thân quặng cao hơn đáng kể so với các mẫu đất bên ngoài thân quặng. Ngoài ra, hoạt độ của hạt nhân phóng xạ trong và ngoài thân quặng cao hơn giá trị trung bình trên toàn thế giới. Đặc biệt trong thân quặng, hoạt độ hoạt độ của các hạt nhân phóng xạ rất cao so với giá trị trung bình của các hạt nhân phóng xạ $\left({ }^{238} \mathrm{U},{ }^{232} \mathrm{Th},{ }^{40} \mathrm{~K}\right)$ trong đất của các nước khác trên thế giới (UNSCEAR, 2000). Giá trị liều hiệu dụng hàng năm $\mathrm{H}_{\mathrm{eff}} \geq 10 \mathrm{mSv} /$ năm (mức phải xem xét các hành động can thiệp, để làm giảm liều chiếu xạ xuống dưới mức 10 $\mathrm{mSv} /$ năm) tập trung tại khu vực chứa quặng đất hiếm.

\section{Kết luận}

Các hạt nhân phóng xạ tự nhiên và đánh giá liều hiệu dụng hàng năm tại khu vực mỏ đất hiếm Mường Hum đã được điều tra, đánh giá trong nghiên cứu này. Kết quả nghiên cứu đã góp phần hoàn thiện việc lựa chọn tổ hợp phương pháp khảo sát thành phần môi trường phóng xạ tại mỏ khoáng sản như: đo khí phóng xạ; suất liều chiếu ngoài; phổ gamma; lấy và phân tích hoạt độ các chất phóng xạ trong mẫu đất, nước, thực vật bằng các thiết bị hiện đại, độ nhạy độ tin cậy cao và có thể áp dụng cho các mỏ khoáng sản có đặc điểm tương tự.

Kết quả nghiên cứu cho thấy liều hiệu dụng hàng năm $\mathrm{H}_{\text {eff }}(\mathrm{mSv} / \mathrm{năm})$ trong thân quặng cao hơn so với bên ngoài thân quặng và cao hơn so với trung bình thế giới $(2,4 \mathrm{mSv} / \mathrm{năm})$. Hoạt độ của hạt nhân phóng xạ $\left({ }^{238} \mathrm{U},{ }^{232} \mathrm{Th},{ }^{40} \mathrm{~K}\right)$ của các mẫu đất trong và ngoài thân quặng (gần thân quặng) cao hơn giá trị trung bình trên toàn thế giới (UNSCEAR, 2000).

Kết quả đạt được trong nghiên cứu này là cơ sở để theo dõi tác động của môi trường phóng xạ và đưa ra các giải pháp giảm thiểu ảnh hưởng của các chất phóng xạ đến môi trường sinh thái khi mỏ đi vào khai thác, chế biến quặng đất hiếm trong thời gian tới.

\section{Đóng góp của các tác giả}

Tác giả Nguyễn Văn Dũng hình thành ý tưởng, nội dung và hoàn thành bản thảo cuối của bài báo; Trịnh Đình Huấn xử lý số liệu, hoàn thành nội dung và xây dựng bản thảo trung gian; Phan Văn Tường thu thập số liệu, xử lý số liệu và đọc bản thảo trung gian.

\section{Tài liệu tham khảo}

Azeez, H. H., Mansour, H. H., Ahmad, S. T. (2019). Transfer of natural radioactive nuclides from soil to plant crops. Applied Radiation and Isotopes, 147, 152-158.

Bo Công thương, (2011). Quy hoach chi tiet thăm do, khai thac, che bien va su dung quang phong xa giai đoan đen 2020, co xet đen năm 2030. Hà Nội, 2011.

Bo Khoa học và Công nghe. (2012). Thông tư "Quy định về kiểm soát và đảm bảo an toàn trong chiếu xạ nghề nghiệp và chiếu xạ công chúng", so 19/2012/TT-BKHCN, Hà Noi.

Bùi Tất Hợp, Trịnh Đình Huấn, Nguyễn Phương. (2010). Tổng quan về đát hiếm Viet Nam. Tạp chí địa chất, loạt A 2010, 447-456.

Cengiz,G. B.(2019).Transferfactorsof 226Ra,232Th and $40 \mathrm{~K}$ from soil to pasture-grass in the northeastern of Turkey,Journal of Radioanalytical and Nuclear Chemistry, 319, 83-89.

Duong, N. T., Van Hao, D., Duong, D. T., Phan, T. T., \& Le Xuan, H. (2021). Natural radionuclides and assessment of radiological hazards in Muong Hum, Lao Cai, Vietnam. Chemosphere, 270, 128671.

Duong, V. H., Nguyen, T. D., Kocsis, E., Csordas, A., Hegedus, M., \& Kovacs, T. (2021). Transfer of radionuclides from soil to Acacia auriculiformis trees in high radioactive background areas in North Vietnam. Journal of Environmental Radioactivity, 229, 106530.

Erees FS, Aközcan S, Parlak Y, Çam S. (2006). Assessment of dose rates around Manisa (Turkey).Radiation Measure, 41,598601.

IAEA-TECDOC-1244. (2001). Impact of new environment and safety regulations on uranium exploration, mining, milling and management of its waste, IAEA, Vienna.

ICRP Publication 103. (2007). The 2007 Recommendations of the International Commission on Radiological Protectio. Elsevier Science Ltd.: Amsterdam, The Netherlands, 2007.

ICRP Publication 82. (2000). Protection of the Public in Situations of Prolonged Radiation Exposure. Elsevier Science Ltd.: Amsterdam, The Netherlands, 2000. 
International Atomic Energy Agency (IAEA). (2006). Technical Reports Series No.295. Measurement of Radionuclides in Food and the Environment. A Guidebook, 2006.

KarahanG, Bayulken A., (2000). Assessment of gamma dose rates around Istanbul (Turkey). JEnviron Radioact, 47,213-21.

National Commission for Sanitary Inspection of Russian Epidemiology. (1999). Radiation Safety Standards (NRB-99). Minzdrav Rossii: Moscow, Russia,

Nguyễn Văn Dũng, Trịnh Đình Huấn, Đào Đình Thuần, (2020). Đánh giá sự biến đổi thành phần phóng xạ môi trường trong hoạt động khai thác, chế biến quặng đồng khu mỏ Sin Quyền, tỉnh Lao Cai. Tạp chí KHCN VN, 62(8), 8-12.

QCVN 08-MT (2015)/BTNMT. National Technical Regulation on Surface Water Quality. Socialist RepublicofVietnam.Hanoi,Vietnam, 2015.

TCVN $7538 \quad-\quad 1 . \quad$ (2006). Soil Quality-Sampling: Guidance on the Design of Sampling Programmes.

TCVN 7889, (2008). Natural Radon activity in Buildings Levels and General Requirements of Measuring Methods.

Tiêu chuẩn Viet Nam 9414. (2012). Điều tra đánh giá địa chất môi trường, phương pháp suất liều gamma.
Tiêu chuẩn Việt Nam 9419, (2012). Điều tra địa chất môi trường, phương pháp phổ gamma.

Tiêu chuẩn Việt Nam: TCVN 9415, (2012). Điều tra, đánh giá địa chất môi truòng-phuong pháp xác định liều tưong đương.

Tiêu chuẩn Việt Nam: TCVN 9416, (2012). Điều tra, đánh giá địa chất môi trường phưong pháp khí phóng xạ.

Trần Anh Tuấn, (2012). Nghiên cúu cơ sở khoa học để xác định khu vực có mức chiếu xạ tự nhiên có khả năng gây hại cho con người để tiến hành khảo sát, đánh giá. Đề tài khoa học công nghệ cấp Bộ (2011 - 2012), Bộ TN \& MT.

Trần BìnhTrọng, Nguyễn Phương, Trịnh Đình Huấn, (2005). Báo cáo Điều tra hiện trạng môi trường phóng xạ trên các mỏ Đông Pao, Thèn Sin - Tam Đường - tỉnh Lai Châu, Mường Hum tỉnh Lào Cai, Yên Phú tỉnh Yên Bái, Thanh Son tỉnh Phú Thọ, An Điềm, Ngọc Kinh - sườn Giữa tỉnh Quảng Nam, Luu trũ Liên đoàn địa chất Xạ Hiếm.

UNSCEAR, (2000). Sources and effects of ionizing radiation, United Nations Scientific Committee on the Effects of Atomic Radiation, New York, 2000.

Van, H. D., Nguyen, T. D., Peka, A., Hegedus, M., Csordas, A., \& Kovacs, T. (2020). Study of soil to plant transfer factors of 226Ra, 232Th, $40 \mathrm{~K}$ and $137 \mathrm{Cs}$ in Vietnamese crops. Journal of Environmental Radioactivity, 223, 106416. 